\title{
An investigation of the dynamic behavior of 3-D four direction carbon-fibers/epoxy braid composites at various strain rates
}

\author{
B. J. Pang, Z. H. Tan, B. Jia \& B. Z. Gai \\ Hypervelocity Impact Research Center, \\ Harbin Institute of Technology, \\ People's Republic of China
}

\begin{abstract}
The 3-D four-direction braid carbon/epoxy composites have been tested in compression under quasi-static loading and high strain rate loading. And the tests were conducted at strain rates up to 2000 /s by split Hopkinson pressure bar (SHPB) and MTS in the paper. The loading pulses in split Hopkinson pressure bar apparatus were modified by pulse shaping techniques such that the samples are in dynamic stress equilibrium and deformed at a nearly constant strain rate over most of the dynamic compression duration. The results indicated that the peak stress and stiffness along the transverse direction were larger than those along the thickness direction. In addition the effect of the strain rate on peak stress and the stiffness was also discussed in the paper.
\end{abstract}

Keywords: SHPB, braid composite material, high strain rates, pulse shaper.

\section{Introduction}

Composites have applied in the field of aerospace, civil engineering, marine and automobile industries due to their high strength and specific stiffness. Many of the applications of composite materials involve dynamic loading during their service life such as the projectile impact on composite armour. Materials and structures response vary significantly between dynamic loading and quasi-static loading [1-4]. Reliable experimental data under the dynamic loading ensures the safety over the ranges of their applications. The 3-D braid composite is so-called the third generation composite material compared with the 2-D laminates $[5,6]$. 2-D laminates often deformed delaminates when it is suffered the impact 
loading [8]. In order to improve the property of resisting of the impact, 3-D braid composite material is fabricated. It has been used in aerospace and other special fields which involved impact loading. Hence, it is essential to characterize the response of the composite materials to high strain rate loading.

Lots of work has been done about the laminator composites, but less for the braid composites. Ochola et al. [7] studied the static and dynamic strength of the 48 layers of cross-ply carbon fiber and glass fiber epoxy at the strain rate of $10^{-3} / \mathrm{s}$ and $450 / \mathrm{s}$. the experimental results showed that the dynamic material strength for glass fiber epoxy increases with increasing strain rates. The strain to failure for both carbon fiber epoxy and glass fiber epoxy is seen to decrease with increasing of strain rate.

Hosur et al. [8] studied the compressive properties of 32 plies of a DA 4518 unidirectional carbon/epoxy laminated composites at strain rates of 82, 164 and $817 /$ s through thickness, along $0^{\circ}$ and $90^{\circ}$, respectively. The results indicated that the dynamic strength and stiffness exhibited considerable increase as compared with those of quasi-static compression. Hosur et al. [9] conducted compressive tests of 37 layers aerospace grade woven nalyse with SC-15 epoxy resin laminates at various in-plane and off-axis degree direction and strain rates. The results showed that ultimate strength and failure strain of woven carbon/epoxy composites vary considerable with off-axis angle.

El-Hanbak [10] studied the effects of fiber volume fraction and specimen size at high strain rates of 100 to 1000 /s on glass fiber in polyester matrix, viny 1 ester and epoxy resin matrix respectively. Results showed that specimen size slightness influence the high strain rate behaviour, and the strength of composite with vinyl ester nalyse is higher than that of the epoxy and polyester matrix.

Harding [11] investigated the effect of strain rates and specimen geometry on the compression strength of woven glass reinforced epoxy laminates. A cylinder and a thin strip were design in test. The results show that the compression strength and failure strain are strongly dependent on the specimen geometry. However, the material for those two geometry specimens are different.

On the basis of these previous investigations, it is clear that the effects of the strain rates are substantial in the deformation and fracture behaviour of composites. In the present work, the quasi-static and high strain rate compressive properties of 3-D braid carbon/epoxy composites in the through thickness direction were tested on a MTS 810.23 tester and a split Hopkinson pressure bar respectively. The effect of strain rate on the peak compressive stress, the stiffness and failure strain is discussed in the study.

\section{Experimental studies}

\subsection{Materials and the specimen fabrication}

The braid angle of $30^{\circ}$ was selected to study the strain rate effect in the paper. The weave construction of 3-D four directional composite materials is shown in Fig. 1. The $12 \mathrm{~K}$ fiber cluster of T300 Carbon fibers were employed to weave the 3-D angle-interlock fabric. The TDE-85 epoxy resins were injected into the 3-D 
woven fabric performs by RTM technique and then consolidated into 3-D composites. The thickness of the composites is $9 \mathrm{~mm}$. The cross section small block 3 -D braid composite specimen with two geometry size $9 \times 9 \times 20 \mathrm{~mm}^{3}$ and $9 \times 9 \times 9 \mathrm{~mm}^{3}$ were cut from a carbon/epoxy 3-D four direction braid composite material for compression test along the transverse and thickness direction respectively.

\subsection{Static and high strain rate compression testing}

A hydraulic testing was carried out on samples in an M.T.S. machine in displacement control mode with a constant crosshead speed of $1.27 \mathrm{~mm} / \mathrm{min}$. The load and crosshead displacement response for each test was recorded by the data acquisition system.

In the present study, the conventional SHPB setup consists of A2 hardened steel bar with $12.7 \mathrm{~mm}$ in diameter; the striker bar is $150 \mathrm{~mm}$, the incident bar is $1200 \mathrm{~mm}$ long and transmission bar is $1200 \mathrm{~mm}$. The strain gauges are attached to the middle of the incident bar and transmission bar. The two strain gauges are connected to a Wheatstone bridge circuit in a $1 / 2$ bridge way to nullify axial waves and magnify 2 times of the bending wave. The signals from the bridges are amplified 500 times by AM 502 Differential amplifiers, recorded in a Tekronix TDS500 oscilloscope. The data sampling rate is $25 \mathrm{MHz}$ for all SHPB tests in present work.

For the composite is a brittle material, the limitation of conventional SHPB technique must be recognized. Frew et al. [12] investigated the technique test for brittle material such as ceramic by using a shaper technology. In order to obtain the reliable and consistent experimental result, Copper disks were used at the end of the incident bar to precisely control the profile the loading pulse in order that the specimen deformed at a nearly constant strain rate under dynamically equilibrated stress over the test.

\subsection{Theory of the split Hopkinson bar}

For the high strain rate test, a split Hopkinson bar setup was employed. A schematic of the set-up is shown in Fig. 2. The setup comprises a gas gun chamber, striker bar, incident bar, transmitter bar and the strain gauges attached on the incident bar and transmitter bar. When the striker bar impacts incident bar, an elastic stress compression wave is generated that propagates the incident bar toward the specimen. When the pulse reaches the interface of the incident bar and specimen, a portion of stress wave is reflected back into the bar as tensile pulse and remaining portion is transmitted into the specimen as a compressive wave toward transmission bar. And stress wave signal is recorded by the gages mounted on the middle of the incident bar and the transmission bar.

Based on the well-known one-dimensional analysis of wave propagation in the bars, the axial stress in the specimen, the strain rate and the strain are estimated as following: 
120 Structures Under Shock and Impact IX

$$
\begin{gathered}
\sigma(t)=\frac{E A_{0}}{A} \varepsilon_{t}(t) \\
\varepsilon(t)=\frac{2 C_{0}}{L_{0}} \int_{0}^{t} \varepsilon_{r}(t) d t \\
\varepsilon(t)=\frac{2 C_{0}}{L_{0}} \varepsilon_{r}(t)
\end{gathered}
$$

where $C_{0}$ is the longitudinal wave velocity in the split Hopkinson bar, $L_{0}$ is the effective gage length of the specimen, $E$ is the Young's modulus of the bar, while $A$ and $A_{0}$ are the cross-sectional areas of the split bar.

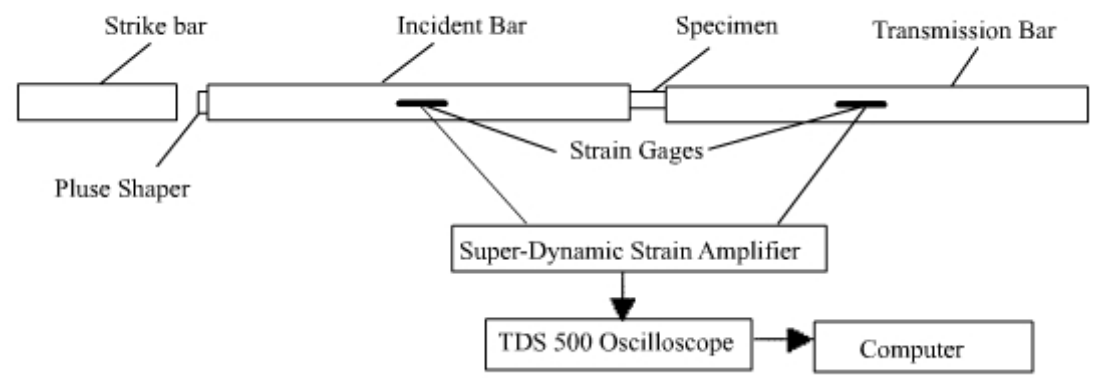

Figure 1: Schematic of split Hopkinson pressure bar.

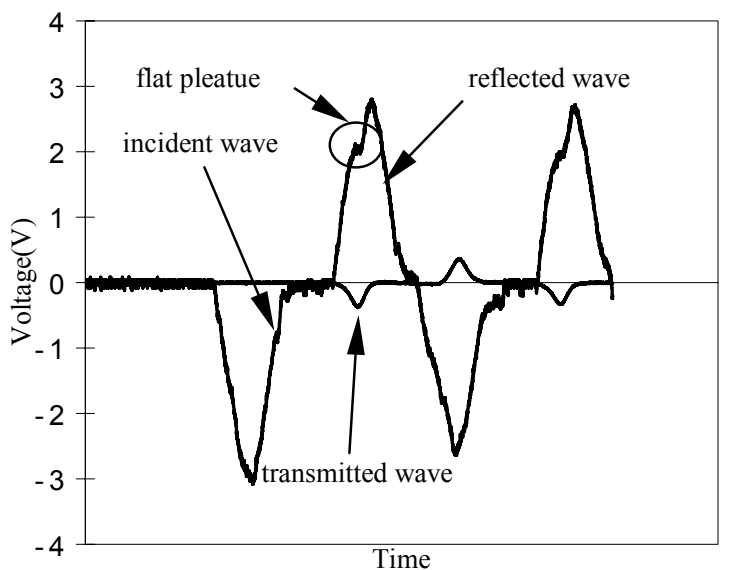

Figure 2: Typical signals of input and output wave in incident and transmission bars. 


\section{Results and discussion}

High strain rate tests were performed on carbon/epoxy braid composite material in transversal and thickness direction at different strain rates, up to 2000/s. Quasi-static tests were conducted to compare with the dynamic response.

The dynamic compression tests were conducted along the transverse and thickness direction, respectively. And the copper disc with diameter of $5 \mathrm{~mm}$ was used as the pulse shaper to ensure the specimens deformed at a constant strain rate. Typical signals of input and output wave in incident and transmission bars are shown in Fig. 2. From the Fig. 2 we can see the reflect wave have a flat and then ascend quickly. The flat plateau means that the specimen deformed at constant strain rate. The ascend part means that the specimen failed and the stress wave reflected completely, and the transmission wave decrease to zero at the same time. The experiment is conduct under the pressure of $0.6 \mathrm{MPa} 0.75 \mathrm{MPa}$ $0.9 \mathrm{MPa} 1.05 \mathrm{MPa}$.

\subsection{Static experimental data}

Fig. 3 illustrates the stress-strain curve of quasi-static compression loading along the transverse and thickness direction. The stiffness of transverse direction is larger than that of the thickness direction. The value of the stiffness is 900GPa for transverse and thickness direction, respectively. However, the peak stress is larger than that of. And the composite shows good ductile property in transverse direction.

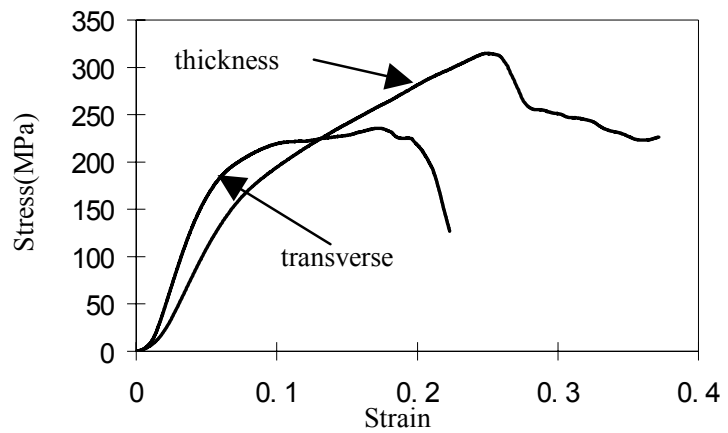

Figure 3: The Quasi-static compression stress-strain curve of composite along the thickness and transverse direction.

\subsection{Loading case along the transverse direction}

The typical stress-strain and strain rates-time curves and values of stiffness and peak stress obtained from experiments in transverse direction at strain rate from 297/s to 488/s are shown in Fig. 4, Fig. 5 and Table 1. The stress strain curves are essential linear before it drops down. The stiffness in transverse direction for 
dynamic loading case for high strain rate is 6 times higher than that for static loading. The effect of strain rate on Young's modulus is little. The stiffness shows some scatter around $23 \mathrm{GPa}$ at low strain rate up to $400 / \mathrm{s}$, and a rapid rise in stiffness is observed beyond a strain rate of $400 / \mathrm{s}$. The value of the stiffness is 4.03GPa for static loading and 24.32, 23.11, 23.54, 33.36GPa for the strain rate of $297,356,412,488 / \mathrm{s}$, respectively. However, the peak stress increases with the increase of the strain rate. And the dynamic peak stress is also higher than that of static. The peak stress increased from 303MPa to $485 \mathrm{MPa}$ at strain rate of $297 / \mathrm{s}$ to $488 / \mathrm{s}$. The value of the peak stress is $236.24 \mathrm{MPa}$ for static and 303.56324 .42 $382.23485 .02 \mathrm{MPa}$ respectively for strain rate of $297,356,412,488 / \mathrm{s}$.

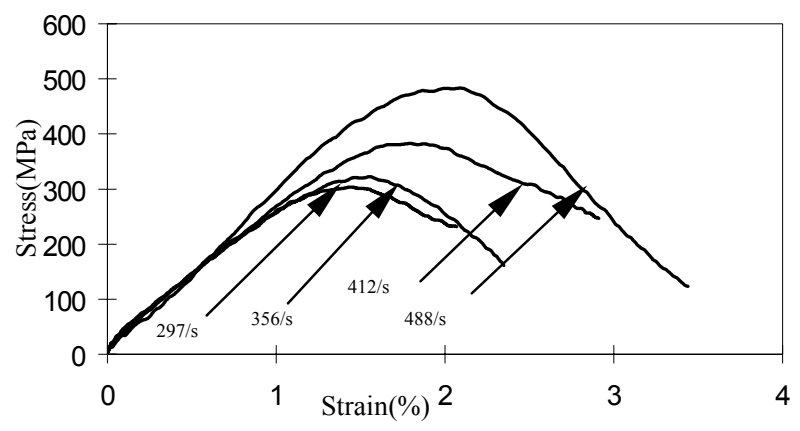

Figure 4: Dynamic compression stress-strain response of composite loaded along transverse direction.

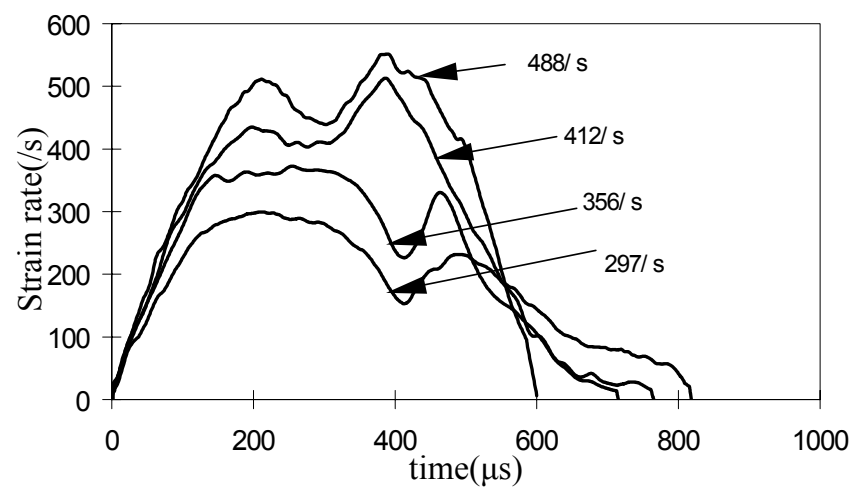

Figure 5: $\quad$ Strain rate -time curve at different strain rate for composite loaded along transverse direction. 
Table 1: Compression properties of composite under various strain rates compression loading along transverse direction.

\begin{tabular}{|c|c|c|}
\hline Strain rate & Peak stress $(\mathrm{MPa})$ & Slope of stress-strain curve $(\mathrm{GPa})$ \\
\hline static & 236.24 & 4.03 \\
\hline 297 & 303.56 & 24.32 \\
\hline 356 & 324.42 & 23.11 \\
\hline 412 & 382.23 & 23.54 \\
\hline 488 & 485.02 & 33.36 \\
\hline
\end{tabular}

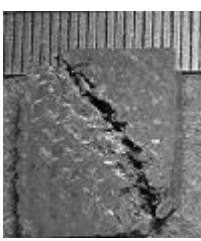

Quasi-static

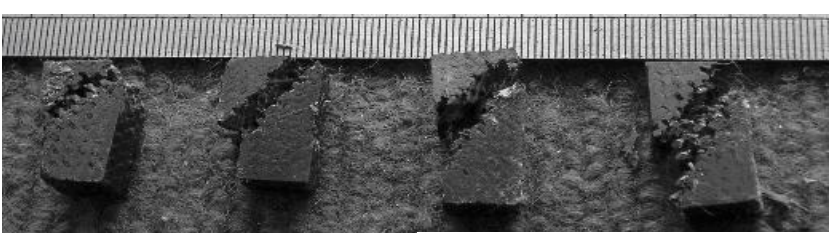

$297 / \mathrm{s}$

$356 / \mathrm{s}$

$412 / \mathrm{s}$

$488 / \mathrm{s}$

Figure 6: Compressive failure at various strain rates in transverse direction.

The failure strain of the quasi-static is much larger than that of the high strain rate is shown in Fig. 6. It is clear that the specimen deformed expansion in axial direction at static loading, and at the high strain rate the failure is shear fracture. The behaviour at the quasi-static has good ductility, and the composites at the high strain rate show brittle property.

Table 2: Compression properties of composite under various strain rates compression loading along thickness direction.

\begin{tabular}{|c|c|c|}
\hline Strain rate & Peak stress $(\mathrm{MPa})$ & Slope of stress-strain curve $(\mathrm{GPa})$ \\
\hline Static & 314.65 & 2.91 \\
\hline $845 / \mathrm{s}$ & 379.80 & 20.22 \\
\hline $1135 / \mathrm{s}$ & 273.0 & 14.66 \\
\hline $1535 / \mathrm{s}$ & 239.6 & 11.96 \\
\hline $1884 / \mathrm{s}$ & 366.82 & 19.67 \\
\hline
\end{tabular}

\subsection{Loading case along the thickness direction}

Fig. 7, Fig. 8 and Table 2 illustrate the stress-strain, strain rate-time curves and values of stiffness and peak stress of braid composite loaded along the thickness direction at strain rates of the $845,1135,1535,1884 / \mathrm{s}$ The stiffness in thickness direction for high strain rate is 8-10 times higher than that for static loading. The stiffness decreases with the increase in strain rate from $845 / \mathrm{s}$ to $1535 / \mathrm{s}$, and then increases for strain rate of $1884 / \mathrm{s}$. The value of the stiffness is $2.91 \mathrm{GPa}$ for static loading and 20.22, 14.66, 11.96, 19.67GPa for the strain rate of $845,1135,1535$, $1884 / \mathrm{s}$, respectively. In additional, the dynamic peak stress has the same trend of the variety of the stiffness. The value of the peak stress is $314.65 \mathrm{MPa}$ for static and $379.8,237,239.6,366.82 / \mathrm{s}$ respectively for strain rates of $845,1135,1535$, $1884 / \mathrm{s}$. 
124 Structures Under Shock and Impact IX

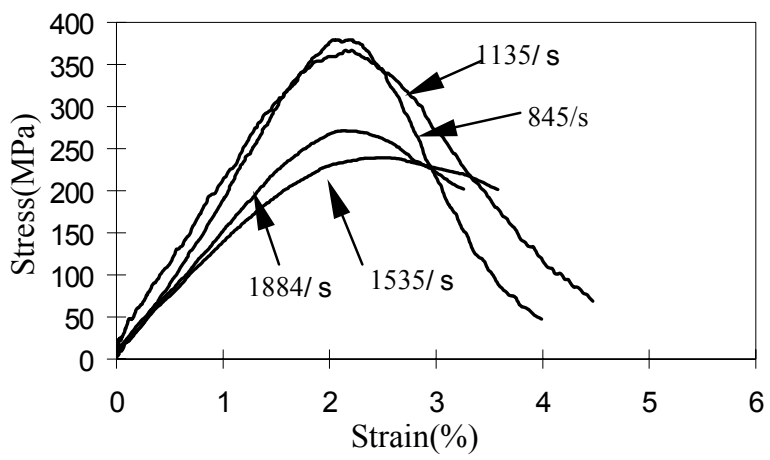

Figure 7: Dynamic compression stress-strain response of composites loaded through thickness.

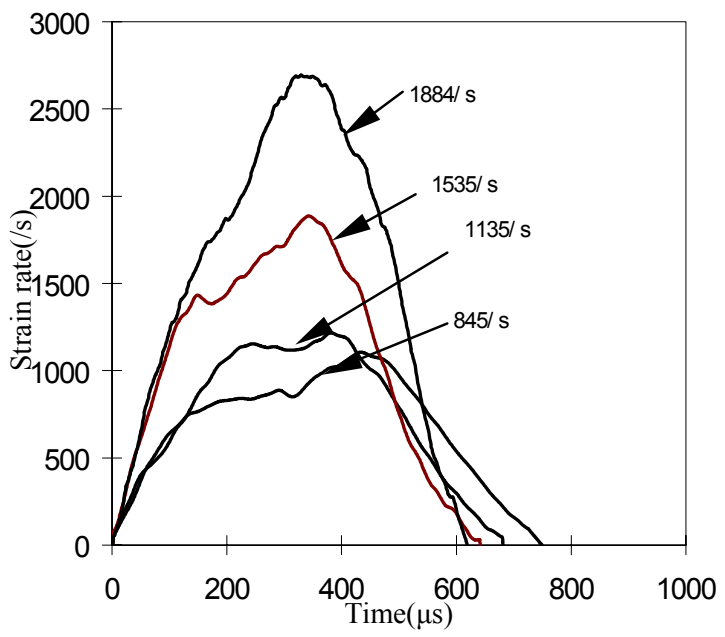

Figure 8: $\quad$ Strain rate -time curve at different strain rate for composite.

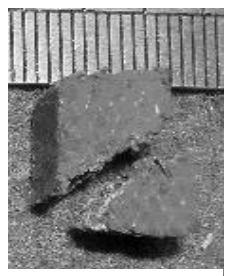

Quasi-static

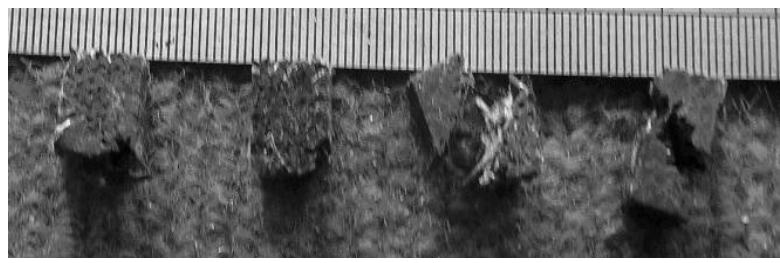

$845 / \mathrm{s}$

$1135 / \mathrm{s}$

$1535 / \mathrm{s}$

$1884 / \mathrm{s}$

Figure 9: Compressive failure at various strain rates through thickness. 
Fig. 9 is the photograph of composites compressive failure at various strain rates. It is obvious that the damage of the composites is rate sensitive. The results of the experiment along the thickness and transverse direction indicate that the peak stress and stiffness are dependent on strain rate. And the property for transverse and thickness direction is different. The stiffness and the peak stress of the transverse are larger than that of thickness at the high strain rate.

\section{Summary and conclusion}

Investigations were carried out on carbon epoxy braid composites under high strain rate loading. The properties of transverse and thickness directions at high strain rates were studied. The static and the high strain rate tests were conducted using M.T.S. and a modified split Hopkinson pressure bar. The copper disks were selected to use as pulse shaper to ensure the samples were in dynamic stress equilibrium and deformed at a nearly constant strain rate over most of the dynamic compression duration The samples were subject the dynamic loading along the thickness and the transverse direction at various strain rates, up to 2000/s. Quasi-static tests results were compared with the results of the high strain rate loading. Following conclusions were drawn from the tests:

1. The peak stress and stiffness under dynamic loading are considerable lager than those of quasi-static along both transverse and thickness directions;

2. The peak stress increases with the increase of the strain rate along the transverse, however the effect of the strain rate on the stiffness along transverse is little;

3. The peak stress decreases with the increase of strain rate first, and then increase with the increase of strain rate, and the effect of strain rate on the stiffness along thickness is obvious;

4. The peak stress of transverse is slight larger than that of the thickness;

5. The failure mode of the high strain rate is different with that of the quasi-static. It is easier to deform in thickness compared with the transverse direction. It shows brittle property at the high strain rate, whereas it shows ductile behaviour at quasi-static loading along the transverse.

\section{References}

[1] Li Z., Lambros J., Determination of the dynamic response of brittle composites by use of the split Hopkinson pressure bar. Composites science and technology, 59, pp.1097-1107, 1996.

[2] Hosur, M.V., Adya, M., Vaidya, U.K., Mayer, A., Jeelani, S., Effect of stitching and weave architecture on the high strain rate compression response of affordable woven carbon/epoxy composites. Composite structures. 59, pp.507-523, 2003.

[3] Oguni, K., Ravichandran G., Dynamic compressive behavior of unidirectional E-glass/vinylester composites. Journal of material science, 36, pp.831-838, 2001. 
[4] Bing, Q.D., Sun, C.T., Modeling and testing strain rate-dependent compressive strength of carbon/epoxy composites. Composites science and technology, 65, pp.2481-2491, 2005.

[5] Mouritz, A.P., Bannister, M.K., Falzon, P.J., Leong, K.H., Review of applications for advanced three-dimensional fibre textile composites. Composites Part A, 30, pp. 1445-1461, 1999.

[6] Sun, B.Z., Gu, B.H., Ding, X., Compressive behavior of 3-D angleinterlock woven fabric composites at various strain rates. Polymer Testing, 24, pp.447-454, 2005.

[7] Ochola, R.O., Marcus, K., Nurick, G.N., Franz, T., Mechanic behavior of glass and carbon fiber reinforced composites at varying strain rates. composite structures, 63, pp. 455-467, 2004.

[8] Hosur, M.V., Alexander, J., Vaidya, U.K., Jeelani, S., High strain rate compression response of carbon/epoxy laminate composites. Composite structures, 52, pp. 405-417, 2001.

[9] Hosur, M.V., Alexander, J., Vaidya, U.K., Jeelani, S., Mayer, A., Studies on the off-axis high strain rate compression loading of satin weave carbon/epoxy composites. Composites structures, 63, pp. 75-85, 2004.

[10] EL-Habak AMA, Compressive resistance of unidirectional GFRP under high strain rate of loading, Journal of Composites Technology. 15(4), pp.311-317, 1993

[11] Harding, J., Effect of strain rate and specimen geometry on the compressive strength of woven glass-reinforced epoxy laminates. Composites, 24, pp.232-233, 1993

[12] Frew, D.J., Forrestal, M.J., Chen, W., Pulse shaping techniques for testing brittle materials with a split Hopkinson pressure bar. Experimental mechanics, 42(1), pp. 93-106, 2002. 